\title{
Rhythm outcome predictors after concomitant surgical ablation for atrial fibrillation: A 9-year, single-center experience
}

\author{
Simon Pecha, MD, Timm Schäfer, MD, Irina Subbotina, MD, Teymour Ahmadzade, MD, \\ Hermann Reichenspurner, MD, PhD, and Florian Mathias Wagner, MD
}

\begin{abstract}
Objectives: Concomitant surgical ablation is a safe and feasible procedure, recommended by the guidelines for patients with atrial fibrillation (AF) undergoing cardiac surgery. We performed a single-center data analysis to identify the predictors of rhythm outcome in such patients.
\end{abstract}

\begin{abstract}
Methods: From January 2003 to January 2012, 503 patients with persistent $(\mathrm{n}=296,58.8 \%)$ or paroxysmal $(\mathrm{n}=207,41.2 \%) \mathrm{AF}$ underwent concomitant surgical AF ablation. The lesions were limited to a pulmonary vein isolation $(\mathrm{n}=76,15.1 \%)$, a more complex left atrial lesion set $(\mathrm{n}=353,70.2 \%)$, or biatrial lesions ( $\mathrm{n}=74,14.7 \%$ ). Follow-up rhythm evaluations were based on either 24-hour Holter electrocardiograms or event recorder interrogation at 3, 6, and 12 months postoperatively. A sinus rhythm (SR) immediately postoperatively was defined as the first documented rhythm after weaning from extracorporeal circulation.
\end{abstract}

Results: The mean patient age was $68.0 \pm 9.5$ years, and $336(66.8 \%)$ were men. No major ablation-related complications occurred. After 1 year of follow-up, $59.9 \%$ of all patients were in SR, with significantly better results in patients with paroxysmal $\mathrm{AF}$ than in those with persistent $\mathrm{AF}(67.3 \%$ vs $54.8 \%, P=.0053)$. Additional statistically significant factors influencing SR after 1 year were left atrial diameter $(P=.0019)$, AF duration $(P=.018)$, and immediate postoperative SR $(P<.001)$. Regarding only patients with persistent or longstanding-persistent AF, those with biatrial lesions had significantly greater rates of conversion to SR than those with solitary left atrial ablation (SR, $64.9 \%$ vs $51.4 \% ; P=.044)$ after 12 months.

Conclusions: The statistically significant predictors for SR after 1 year were left atrial diameter, AF duration, preoperative paroxysmal AF, immediate postoperative SR, and biatrial ablation for persistent AF. (J Thorac Cardiovasc Surg 2014;148:428-33)

Atrial fibrillation (AF) is the most common sustained arrhythmia in patients undergoing cardiac surgery, and its prevalence has been increasing with the aging of populations. AF can lead to heart failure, thromboembolic events, including stroke, and increased hospitalization, with a reduction in quality of life. ${ }^{1,2}$ Therefore, the guidelines have recommended concomitant surgical ablation for patients with $\mathrm{AF}$ who are undergoing cardiac surgery. ${ }^{3}$ Cox first reported his technique of surgical AF ablation using a cut-and-sew principle in 1987, later revised by him to a lesion pattern termed the "Cox maze III procedure." Because of its high success rate in the restoration of sinus rhythm (SR), it became the reference standard for AF surgery. However, owing to complexity of the procedure, only a few surgeons were performing it.

From the Department of Cardiovascular Surgery, University Heart Center Hamburg, Hamburg, Germany.

Disclosures: Authors have nothing to disclose with regard to commercial support. Received for publication June 8, 2013; revisions received Aug 6, 2013; accepted for publication Aug 22, 2013; available ahead of print Oct 21, 2013.

Address for reprints: Simon Pecha, MD, Department of Cardiovascular Surgery, University Heart Center Hamburg, Martinistr 52, Hamburg 20246, Germany (E-mail: s.pecha@uke.de).

$0022-5223 / \$ 36.00$

Copyright (c) 2014 by The American Association for Thoracic Surgery

http://dx.doi.org/10.1016/j.jtcvs.2013.08.074
To facilitate and simplify the procedure, the cut and sew principle was replaced by transmural atrial lesions generated by various thermal energy sources, such as radiofrequency, ultrasonography, or cryotherapy, resulting in the so-called Cox maze IV procedure. Various modified lesion sets, including isolated pulmonary vein ablation, left atrial ablation, and biatrial ablation, have been reported over the years. A meta-analysis by Barnett and $\mathrm{Ad}^{4}$ showed that in randomized controlled trials and nonrandomized trials, statistically greater rates of conversion to SR occurred in patients who had undergone cardiac surgery with concomitant ablation compared with those who had undergone cardiac surgery alone. Prospective, randomized trials have resulted in rates of conversion to SR of $44 \%$ to $94 \%$ for patients undergoing concomitant $\mathrm{AF}$ ablation. ${ }^{5-9}$ However, only a few studies with relatively small numbers of patients have investigated the influence of different lesion sets and energy sources on the outcomes of surgical AF ablation. Therefore, the aim of our study was to analyze the predictors of the 12-month outcome in patients with AF who had undergone concomitant surgical ablation and to determine the effect of different patient factors, energy sources, and lesion sets on the rates of conversion to SR in a large patient cohort with implementation of the current follow-up guidelines. 


$$
\begin{aligned}
& \text { Abbreviations and Acronyms } \\
& \begin{aligned}
\text { AF } & =\text { atrial fibrillation } \\
\text { CABG } & =\text { coronary artery bypass grafting } \\
\text { ECG } & =\text { electrocardiogram } \\
\text { ER } & =\text { event recorder } \\
\text { LA } & =\text { left atrial } \\
\text { LVEF } & =\text { left ventricular ejection fraction } \\
\text { PVI } & =\text { pulmonary vein ablation } \\
\text { SR } & =\text { sinus rhythm }
\end{aligned}
\end{aligned}
$$

\section{METHODS \\ Patients}

From January 2003 to October 2011, 503 patients underwent concomitant surgical ablation because of persistent $(n=296,58.8 \%)$ or paroxysmal $(\mathrm{n}=207,41.2 \%)$ AF. The baseline patient characteristics are listed in Table 1 . The mean patient age was $68.0 \pm 9.5$ years, and $66.8 \%$ were men. Of the 503 patients, $296(58.8 \%)$ had preoperative persistent $\mathrm{AF}$ and $207(41.2 \%)$ had paroxysmal AF. The mean left atrial (LA) diameter was enlarged to $51.0 \mathrm{~mm}$, and the mean left ventricular ejection fraction (LVEF) showed a normal value of $53.5 \%$. A moderate or more severely reduced LVEF of $<40 \%$ was present in 61 patients $(12.1 \%)$. The mean AF duration was 3.4 years, and 51 patients $(10.2 \%)$ had a experienced a thromboembolic or ischemic stroke before surgery. The surgical procedures are listed in Table 2.

\section{Ablation Methods}

The ablation types are listed in Table 3. Isolated pulmonary vein ablation (PVI) was conducted in 76 patients $(15.1 \%)$. This limited lesion set was used in patients with paroxysmal $\mathrm{AF}$ and without planned opening of the atria for the surgical procedure (eg, in patients undergoing coronary artery bypass grafting [CABG] and aortic valve replacement). Extended LA ablation was performed in 353 patients $(70.2 \%)$ using the LA ablation lesion set of the Cox maze IV procedure, with pulmonary vein ablation, box lesion, LA appendage, and isthmus isolation. Since 2008, biatrial ablation was conducted in 74 patients $(14.7 \%)$. This extended ablation regimen was only conducted in patients with persistent or longstanding-persistent AF. The decision of which patients underwent a biatrial or LA lesion set was determined by the surgeon performing the procedure. The right atrial lesion set consisted of intercaval line, isolation of the cavotricuspid isthmus, right atrial appendage, and terminal crest.

The energy sources were argon-based cryoablation in 114 patients (22.7\%) CryoCath Surgical Ablation Probe, Medtronic, Inc, Minneapolis, Minn; and CryoICE Cryoablation probe, Atricure, Inc, West Chester, Ohio), unipolar radiofrequency ablation in 261 (51.8\%; Cardioblate Unipolar RF Pen, Medtronic), and bipolar radiofrequency ablation in 128 (25.5\%; Cardioblate BP2 device and Cardioblate Surgical Ablation System Generator, Medtronic; and Atricure Isolater Synergy Ablation Clamp, Atricure). From 2003 to 2009, epimyocardial cryoablation was used in patients receiving surgical AF ablation without opening the left atrium; all other patients received endomyocardial ablation using unipolar radiofrequency. Since 2009, after introduction of the bipolar radiofrequency clamp in our institution, it has become the preferred tool for all strategies of ablation. Since then, endomyocardial unipolar radiofrequency or cryoablation has only been used in patients requiring mitral valve treatment with either an open sternum transseptal or a minimally invasive thoracic-lateral approach.

\section{Statistical Analysis}

A retrospective, single-center data analysis was accomplished. All statistical analyses were performed using the Statistical Package for
Social Sciences statistical software, version 18.0 (SPSS, Inc, Chicago, Ill). Continuous values are presented as mean \pm standard deviation and were compared using the Student $t$ test. Categorical variables are presented as the frequencies and percentages and were compared using the chi-square test or Fisher's exact test, as appropriate. $P<.05$ was considered statistically significant. The reported $P$ values are 2 -sided. Uni- and multivariate logistic regression analyses were used to identify independent predictors for SR after 12 months. The parameters considered for univariate analysis were age, gender, LA diameter, AF type and duration, LVEF, type of concomitant procedure, lesion set, energy source, and early AF recurrence. For multivariate logistic regression analysis, we included the significant covariates from the univariate analysis and the covariates that in our experience had been considered clinically relevant. These were age, gender, AF type and duration, surgical procedure, LVEF, and LA diameter.

\section{Follow-up Protocol}

Rhythm follow-up was accomplished after 3, 6, and 12 months in all patients using either 24-hour Holter electrocardiograms (ECGs) $(n=353)$ or event recorder $(E R)$ interrogation $(n=149)$. In patients with $\mathrm{ER}, \mathrm{AF}$ recurrence was defined as an $\mathrm{AF}$ burden $>0.5 \%$ and/or a duration of a single AF episode of $>30$ s. ER-documented AF episodes were manually validated. In patients without ER, a 24-hour Holter ECG was recorded at 3,6 , and 12 months postoperatively. In the latter group, any episode of $\mathrm{AF}$ with a duration $>30 \mathrm{~s}$ was regarded as $\mathrm{AF}$ recurrence. Antiarrhythmic drugs and anticoagulation regimens were maintained for 3 months postoperatively in all patients and then adapted according to the ER or 24-hour ECG rhythm results. In patients without a contraindication, amiodarone was used as the first-line antiarrhythmic therapy. Otherwise, other class I or class III antiarrhythmic drugs were prescribed for $\geq 3$ months postoperatively. Antiarrhythmic medical therapy was stopped when the patients were in SR at 3 months of follow-up. Electrical cardioversion was performed in patients with persistent $\mathrm{AF}$ at the follow-up examination. Patients with AF recurrence at 6 months postoperatively were considered for additional catheter-based ablation, if reasonable. Patients receiving additional catheter-based ablation were considered to have failure of surgical $\mathrm{AF}$ ablation for rhythm analysis after 12 months.

\section{RESULTS \\ Perioperative Data and Outcomes}

No major ablation-related complication occurred in any of the patients. A perforation of the posterior wall of the left atrium was present in 1 patient after cryoablation and was sutured without additional complications. No intraoperative deaths occurred. Five patients $(0.9 \%)$ experienced perioperative stroke. The in-hospital mortality was $1.2 \%$, and the 1 -year survival rate was $94.9 \%$. The stroke-free survival rate after 1 year was $97.2 \%$.

Concomitant procedures and ablation type are listed in Table 2. Most procedures included mitral $(\mathrm{n}=151$, $30.0 \%)$ or aortic valve $(\mathrm{n}=53,10.5 \%)$ surgery. CABG was performed in 126 patients $(25.1 \%)$, tricuspid valve replacement in 8 patients $(1.6 \%)$, and aortic surgery in 14 patients $(2.0 \%)$. Combined mitral valve replacement and tricuspid valve replacement was performed in 46 patients $(9.2 \%)$, mitral valve replacement and aortic valve replacement in $25(5.0 \%)$, and mitral valve replacement plus CABG in $58(11.5 \%)$. Other procedures were conducted in 22 patients $(4.4 \%)$. 
TABLE 1. Patient characteristics $(n=503)$

\begin{tabular}{lc}
\hline \multicolumn{1}{c}{ Characteristic } & Value \\
\hline Age (y) & $68.0 \pm 9.5$ \\
Gender & \\
$\quad$ Female & 336 \\
$\quad$ Male & 167 \\
AF duration (y) & $4.0 \pm 3.7$ \\
Paroxysmal AF & $207(41.2)$ \\
Persistent AF & $296(58.8)$ \\
LA diameter (mm) & $51.0 \pm 8.9$ \\
LVEF (\%) & $52.6 \pm 11.0$ \\
LVEF $<40 \%$ & $61(12.1)$ \\
Previous stroke & $51(10.1)$ \\
Diabetes & $95(18.9)$ \\
Renal insufficiency & $55(10.9)$ \\
Preoperative pacemaker use & $34(6.8)$ \\
Peripheral arterial disease & $29(5.8)$ \\
COPD & $51(10.1)$ \\
Coronary artery disease & $240(47.7)$ \\
Previous MI & $50(9.9)$ \\
\hline
\end{tabular}

Data presented as mean \pm standard deviation or $\mathrm{n}(\%) . A F$, Atrial fibrillation; $L A$, left atrial; $L V E F$, left ventricular ejection fraction; $C O P D$, chronic obstructive pulmonary disease; $M I$, myocardial infarction.

\section{Rhythm Results}

The completeness of follow-up was $96 \%$ after 12 months. The overall rate of conversion to SR was $49.8 \%$, $57.6 \%$, and $59.9 \%$ after 3,6 , and 12 months, respectively (Figure 1). In patients with preoperative paroxysmal $\mathrm{AF}$, the rate of conversion to SR after 12 months was significantly greater than that in patients with persistent AF (SR, 67.3\% vs $54.8 \% ; P=.0053$ ). The rate of registered SR did not differ significantly between the ER and Holter-monitored patients after 12 months $(63.2 \%$ vs $58.5 \%$ ). Neither demographic data nor the type of concomitant procedure nor pre-existing disease had a significant effect on SR after 1 year (Table 4).

Radiofrequency ablation was used in 389 patients $(77.3 \%)$, either unipolar $(\mathrm{n}=261)$ or bipolar $(\mathrm{n}=128)$, with a $57.3 \%$ conversion rate to SR in the unipolar and $62.7 \%$ conversion rate to $\mathrm{SR}$ in the bipolar group (Figure 2). Between the 2 groups, no significant differences were found in the preoperative $\mathrm{AF}$ type, with $38.2 \%$

TABLE 2. Surgical procedures $(\mathbf{n}=\mathbf{5 0 3})$

\begin{tabular}{lc}
\hline \multicolumn{1}{c}{ Procedure } & $\mathbf{n}(\%)$ \\
\hline CABG & $130(32.4)$ \\
AVR & $153(38.2)$ \\
MVR & $202(50.4)$ \\
TVR & $47(11.7)$ \\
MVR plus TVR & $50(9.9)$ \\
MVR plus CABG & $50(9.9)$ \\
MVR plus AVR & $39(7.8)$ \\
Aortic surgery & $24(4.8)$ \\
\hline
\end{tabular}

$C A B G$, Coronary artery bypass grafting; $A V R$, aortic valve replacement; $T V R$, tricuspid valve replacement; $M V R$, mitral valve replacement.
TABLE 3. Types of ablation $(n=503)$

\begin{tabular}{lc}
\hline Ablation type & $\mathbf{n}(\%)$ \\
\hline Cryoablation & $114(22.7)$ \\
Radiofrequency & $389(77.3)$ \\
$\quad$ Unipolar & $261(51.9)$ \\
Bipolar & $128(25.4)$ \\
LA & $353(70.2)$ \\
Biatrial & $74(14.7)$ \\
PVI & $76(15.1)$ \\
\hline$L A$, Left atrial; $P V I$, pulmonary vein ablation.
\end{tabular}

paroxysmal $\mathrm{AF}$ in the unipolar and $44.3 \%$ in the bipolar group $(P=.12)$. Cryoablation was performed in 114 patients $(22.7 \%)$, with a $60.7 \%$ conversion rate to SR. All together, the type of energy source used did not significantly influence the restored SR rate after 12 months.

Complete left-sided ablation was accomplished in 353 patients $(70.2 \%)$, and pulmonary vein isolation only was conducted in $76(15.1 \%)$. PVI was only used in patients with paroxysmal AF. In the population with paroxysmal $\mathrm{AF}$, no statistically significant difference was found in the SR rate after 12 months between patients with a complete LA lesion set and those with only PVI $(69.3 \%$ vs $64.4 \%$, $P=.43$; Figure 3). In the 296 patients with persistent and longstanding-persistent $\mathrm{AF}$, those with biatrial lesion sets had significantly greater rates of SR after 1 year than the LA ablation group (SR, $64.9 \%$ vs $51.4 \% ; P=.044$; Figure 4). Additional predictors for SR after 12 months were the LA diameter and AF duration. Patients with a smaller LA diameter $(P=.0019)$ and shorter AF duration $(P=.018)$ had significantly greater rates of SR after 1 year. Stratifying the patients into groups with different LA diameters, patients with an LA diameter $<5 \mathrm{~cm}, 5$ to 6 $\mathrm{cm}$, and $>6 \mathrm{~cm}$ had a sinus rhythm rate of $66.2 \%, 59.3 \%$, and $44.1 \%$, with a statistically significant lower SR rate in patients with an LA diameter $>6 \mathrm{~cm}(P<.001)$. SR immediately postoperatively $(68.6 \%$ SR after 1 year, $P<.001)$ was an independent predictor of SR after 1 year.

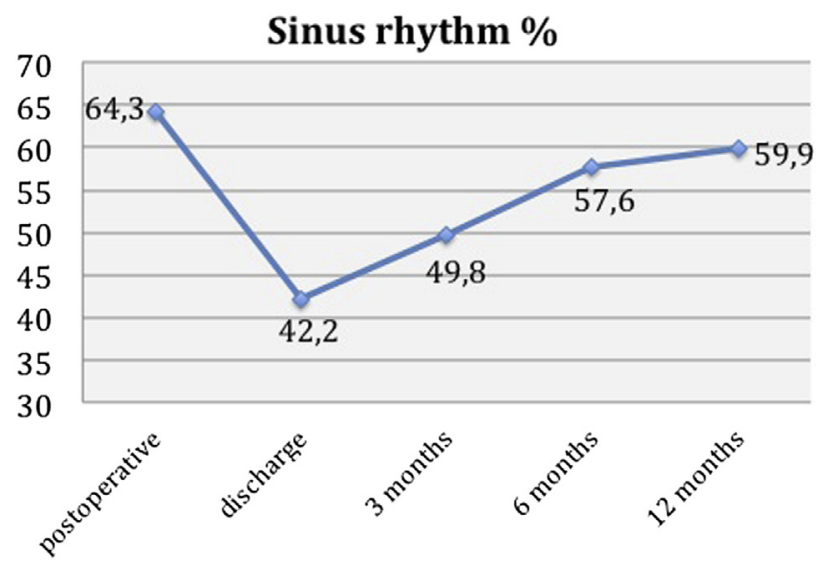

FIGURE 1. Sinus rhythm rate during follow-up. 
TABLE 4. Influence of patient factors and procedures on sinus rhythm rate after 12 months by multivariate logistic regression analysis

\begin{tabular}{lc}
\hline \multicolumn{1}{c}{ Variable } & $\boldsymbol{P}$ value \\
\hline Age (y) & .723 \\
Male gender & .179 \\
Paroxysmal AF & $.005^{*}$ \\
LA diameter & $.002^{*}$ \\
AF duration & $.019 *$ \\
Coronary artery disease & .155 \\
Preoperative LVEF & .256 \\
CABG & .058 \\
AVR & .266 \\
MVR & .096 \\
Cryoablation & .837 \\
Radiofrequency unipolar & .218 \\
Radiofrequency bipolar & .277 \\
LA lesion set & .308 \\
PVI & .859 \\
Biatrial lesion set & .343 \\
Immediate postoperative SR & $<.001 *$ \\
\hline
\end{tabular}

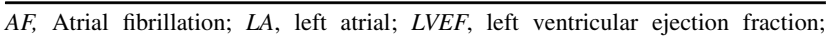
$C A B G$, coronary artery bypass grafting; $A V R$, aortic valve replacement; $M V R$, mitral valve replacement; $P V I$, pulmonary vein ablation; $S R$, sinus rhythm. *Paroxysmal $\mathrm{AF}$, .0053; LA diameter, .0019; AF duration, .018; immediate postoperative SR, .001.

Additional catheter-based ablation was performed in 26 patients $(5.2 \%)$, and electrical cardioversion was conducted in 54 patients $(10.7 \%)$ within 1 year of follow-up.

\section{DISCUSSION}

The original Cox maze procedure, first reported by Cox in 1987, was revised to the Cox maze III procedure, which became the reference standard for $\mathrm{AF}$ ablation. In many comparisons, the Cox maze III procedure has been reported to be the most effective therapy for AF, resulting in success rates of $\leq 99 \% .^{10,11}$ Replacing the original cut and sew principles by ablation with different energy sources to

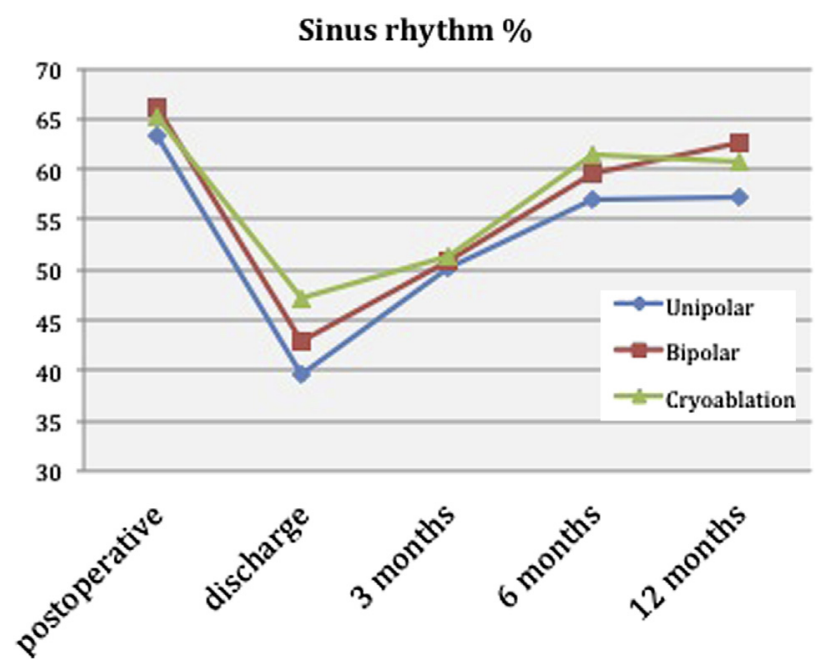

FIGURE 2. Sinus rhythm rate stratified by different energy sources.

\section{Paroxysmal AF Sinus Rhythm \%}

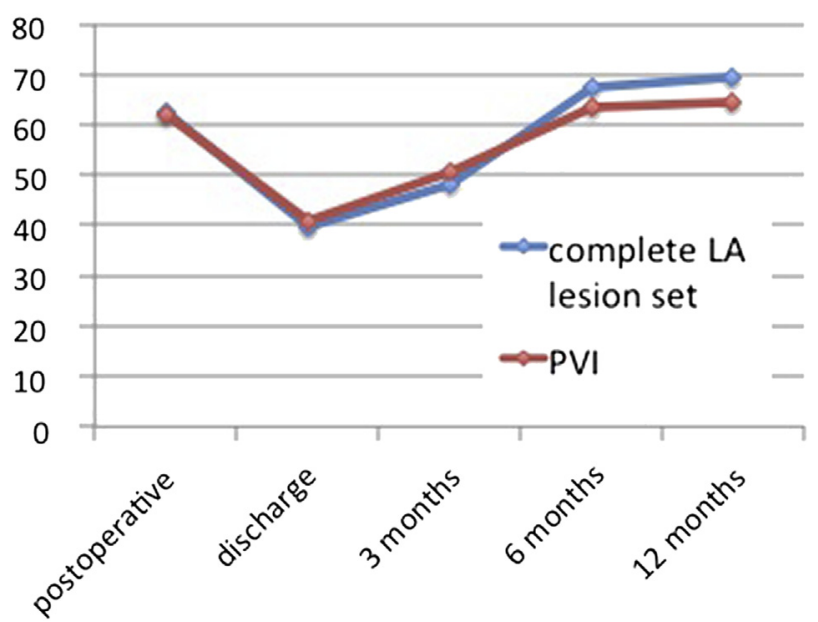

FIGURE 3. Sinus rhythm rate during follow-up in patients with paroxysmal atrial fibrillation $(A F)$. $L A$, Left atrial; $P V I$, pulmonary vein ablation.

create transmural thermal atrial lesions led to the Cox maze IV procedure. This modified Cox maze procedure has been shown to be as effective as the classic cut and sew maze technique. Lall and colleagues ${ }^{12}$ showed similar results in a propensity score-matched analysis for patients undergoing the Cox maze III and IV procedures, with a success rate of $96 \%$ and $93 \%$, respectively, after 1 year of follow-up. Surgical AF ablation can be conducted either as a standalone or concomitant procedure. In the present study, we have reported our experience with surgical AF ablation as a concomitant procedure.

To date, 6 prospective randomized trials have reported the results of concomitant surgical ablation for patients with AF. The largest trial included 97 patients with

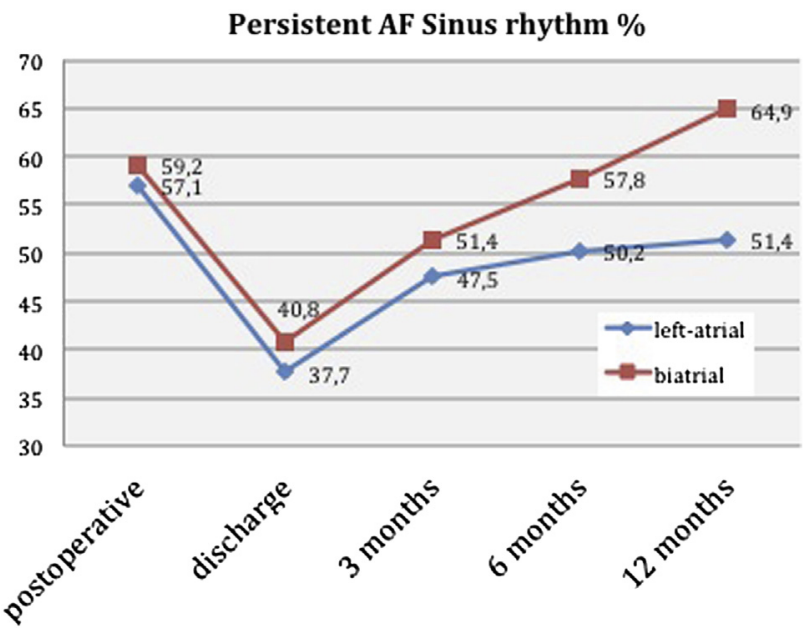

FIGURE 4. Sinus rhythm rate during follow-up in patients with persistent atrial fibrillation $(A F)$. 
persistent AF who were referred for mitral valve surgery. The patients were randomized to either mitral valve surgery and LA radiofrequency ablation or mitral valve surgery only. Patients with concomitant ablation showed significantly greater rates of SR after 1 year $(44 \%$ vs $4.5 \%) .{ }^{9}$ This finding was replicated in other prospective randomized trials. ${ }^{5-8}$ The rates of SR ranged from $57 \%$ to $82 \%$ in these studies. However, because of the small number of patients and the resulting limited statistical power, none of the randomized trials was able to show a survival benefit for patients receiving concomitant ablation. However, in a recent propensity score-matched analysis by McCarthy and colleagues, ${ }^{13}$ the midterm survival of patients with AF receiving concomitant surgical ablation was significantly greater statistically compared with the untreated patients and comparable to those of patients without preoperative AF.

Great variability was also found in the ablation success rates in recent retrospective studies, with SR rates ranging from $67 \%$ to $84 \%$ in patients with $\mathrm{AF}$ undergoing concomitant surgical ablation. ${ }^{14-20}$ These variations were most likely the result of the use of different lesion sets, energy sources, surgeon experience, and implemented follow-up strategies, which varied from symptom-oriented patient interviews to continuous rhythm monitoring.

Our retrospective data series contained a large number of patients treated during a long period and using different line sets and energy sources for AF ablation. We found that the energy source type used for ablation did not have any effect on SR after 12 months, which has also been seen in previously published studies. ${ }^{20,21}$ However, a few reports, although none prospective, have been published reporting that the success of ablation depended on energy source used.

Regarding the different lesion sets, a study by Gillinov and colleagues ${ }^{14}$ and a meta-analysis by Barnett and $\mathrm{Ad}^{4}$ have shown biatrial lesion sets to be superior to LA lesion sets in patients with persistent AF. This finding was supported in our series in the multivariate analysis when assessing only patients with persistent AF. A significantly greater SR rate was seen in patients with biatrial lesion sets than in those receiving only LA ablation. However, a greater incidence of postoperative permanent pacemaker implantation was observed in patients receiving a biatrial lesion set in a study by Worku and colleagues ${ }^{22}$ and in our previously published data. ${ }^{23}$

The present study is 1 of the first series to implement the recent guidelines for follow-up. ${ }^{3}$ All rhythm results were collected using either 24-hour Holter ECG or ER interrogation. All patients had $\geq 1$ 24-hour Holter ECG or ER interrogation at 3 and 12 months of follow-up. Especially in patients with paroxysmal AF, this allowed a more accurate analysis of the actual rhythm and ablation success rates. Previous studies have shown that short-term rhythm monitoring underestimates the rate of $\mathrm{AF}$ recurrence after ablation therapy, ${ }^{24,25}$ and the more extended follow-up period might have been the reason for the lower SR rates compared with the previously published results of surgical AF ablation with less extensive followup strategies. Gillinov and colleagues ${ }^{14}$ reported in a retrospective study a rate of SR of $76 \%$ at 1 year after surgical AF ablation in patients with persistent AF. However, the rhythm results were based only on the ECG findings, and the conversion rate might have been lower if the results had included repeated 24-hour Holter ECG or continuous rhythm monitoring using ER.

On multivariate analysis, no association was found between gender, age, coronary artery disease, LVEF, and the type of concomitant procedure and the rates of SR after 1 year. In previously published studies, ${ }^{14,17}$ older age resulted in a greater rate of $\mathrm{AF}$ recurrence; however, we could not confirm this finding in our study.

In the present study, a LA diameter $>6 \mathrm{~cm}$ was an independent predictor for successful ablation. Similar observations were reported by Damiano and colleagues ${ }^{15}$ and Gillinov et al. ${ }^{18,19}$ The AF duration was also an independent predictor of greater rates of SR after 1 year. This result was supported in a previous study by Gaynor and colleagues ${ }^{16}$ but could not be confirmed in their more recent analysis for predictors of late recurrence in Cox maze IV procedures.

Immediate postoperative SR was an independent predictor of ablation success after 12 months. Similar results have been published by Damiano and colleagues. ${ }^{15}$ They found that patients with early recurrence of atrial tachycardias also had greater rates of AF recurrence after 1 year. ${ }^{15}$ All our patients received amiodarone for 3 months postoperatively. It remains unknown whether a more extensive cardioversion regimen with additional electrical cardioversion in patients with early recurrence of atrial tachycardia would have improved the long-term outcomes, although it is probable that early recurrence of atrial tachycardia is also evidence for the presence of an additional pathologic atrial substrate that maintains these arrhythmias. Additional investigation is needed to address this question.

Our success rates were significantly greater in patients with preoperative paroxysmal $\mathrm{AF}$ than in those with persistent AF, just as previously published, ${ }^{14,18,19}$ and was not surprising. In patients with paroxysmal $\mathrm{AF}$, reentry circuits play a major role, and a pathologic substrate available to sustain atrial tachyarrhythmias is likely less. ${ }^{26}$

A major limitation of the present study was that we used a nonrandomized retrospective study design, in which unknown confounders and selection and detection bias could not be completely avoided. Furthermore, the present study was a single-center analysis. 
Concomitant surgical ablation for AF showed a SR conversion rate of $59.9 \%$ after 1 year of follow-up. The statistically significant predictors for SR after 1 year were preoperative paroxysmal AF, LA diameter, AF duration, and SR immediately postoperatively. In patients with persistent AF, those receiving a biatrial lesion set showed a statistically significant greater SR conversion rate after 12 months of follow-up. However, different energy sources and the type of concomitant procedure did not influence the SR rate.

Because of previously published data and our own experience, our current ablation strategy includes a biatrial lesion set in patients with persistent AF. In most patients with paroxysmal AF, a complete LA lesion set is performed, and only PVI is performed in patients undergoing off-pump CABG and some of the patients undergoing aortic valve replacement or CABG without opening the left atrium.

\section{References}

1. Fuster V, Rydén LE, Cannom DS, Crijns HJ, Curtis AB, Ellenbogen KA, et al. $2011 \mathrm{ACCF} / \mathrm{AHA} / \mathrm{HRS}$ focused updates incorporated into the ACC/AHA/ESC 2006 guidelines for the management of patients with atrial fibrillation: a report of the American College of Cardiology Foundation/American Heart Association Task Force on Practice Guidelines developed in partnership with the European Society of Cardiology and in collaboration with the European Heart Rhythm Association and the Heart Rhythm Society. J Am Coll Cardiol. 2011;57:e101-98.

2. Flaker GC, Belew K, Beckman K, Vidaillet H, Kron J, Safford R, et al; AFFIRM Investigators. Asymptomatic atrial fibrillation: demographic features and prognostic information from the Atrial Fibrillation Follow-up Investigation of Rhythm Management (AFFIRM) study. Am Heart J. 2005; 149:657-63.

3. Calkins H, Kuck KH, Cappato R, Brugada J, Camm AJ, Chen SA, et al; Heart Rhythm Society Task Force on Catheter and Surgical Ablation of Atrial Fibrillation. 2012 HRS/EHRA/ECAS expert consensus statement on catheter and surgical ablation of atrial fibrillation: recommendations for patient selection, procedural techniques, patient management and follow-up, definitions, endpoints, and research trial design: a report of the Heart Rhythm Society (HRS) Task Force on Catheter and Surgical Ablation of Atrial Fibrillation. Developed in partnership with the European Heart Rhythm Association (EHRA), a registered branch of the European Society of Cardiology (ESC) and the European Cardiac Arrhythmia Society (ECAS); and in collaboration with the American College of Cardiology (ACC), American Heart Association (AHA), the Asia Pacific Heart Rhythm Society (APHRS), and the Society of Thoracic Surgeons (STS). Endorsed by the governing bodies of the American College of Cardiology Foundation, the American Heart Association, the European Cardiac Arrhythmia Society, the European Heart Rhythm Association, the Society of Thoracic Surgeons, the Asia Pacific Heart Rhythm Society, and the Heart Rhythm Society. Heart Rhythm. 2012;9:632-96.e21.

4. Barnett SD, Ad N. Surgical ablation as treatment for the elimination of atrial fibrillation: a meta-analysis. J Thorac Cardiovasc Surg. 2006;131:1029-35.

5. Abreu Filho CA, Lisboa LA, Dallan LA, Spina GS, Grinberg M, Scanavacca M, et al. Effectiveness of the maze procedure using cooled-tip radiofrequency ablation in patients with permanent atrial fibrillation and rheumatic mitral valve disease. Circulation. 2005;112(9 Suppl):I20-5.

6. Deneke T, Khargi K, Grewe PH, Laczkovics A, von Dryander S, Lawo T, et al Efficacy of an additional MAZE procedure using cooled-tip radiofrequency ablation in patients with chronic atrial fibrillation and mitral valve disease: a randomized, prospective trial. Eur Heart J. 2002;23:558-66.

7. Schuetz A, Schulze CJ, Sarvanakis KK, Mair H, Plazer H, Kilger E, et al. Surgical treatment of permanent atrial fibrillation using microwave energy ablation: a prospective randomized clinical trial. Eur J Cardiothorac Surg. 2003;24:475-80.

8. Blomström-Lundqvist C, Johansson B, Berglin E, Nilsson L, Jensen SM, Thelin S, et al. A randomized double-blind study of epicardial left atrial cryoablation for permanent atrial fibrillation in patients undergoing mitral valve surgery: the SWEDish Multicentre Atrial Fibrillation study (SWEDMAF) Eur Heart J. 2007;28:2902-8.

9. Doukas G, Samani NJ, Alexiou C, Oc M, Chin DT, Stafford PG, et al. Left atrial radiofrequency ablation during mitral valve surgery for continuous atria fibrillation: a randomized controlled trial. JAMA. 2005;294:2323-9.

10. Cox JL, Ad N, Palazzo T, Fitzpatrick S, Suyderhoud JP, DeGroot KW, et al. Current status of the maze procedure for the treatment of atrial fibrillation. Semin Thorac Cardiovasc Surg. 2000;12:15-9.

11. McCarthy PM, Gillinov AM, Castle L, Chung M, Cosgrove D III. The Cox-maze procedure: the Cleveland Clinic experience. Semin Thorac Cardiovasc Surg. 2000; $12: 25-9$.

12. Lall SC, Melby SJ, Voeller RK, Zierer A, Bailey MS, Guthrie TJ, et al. The effect of ablation technology on surgical outcomes after the Cox-maze procedure: a propensity analysis. J Thorac Cardiovasc Surg. 2007;133:389-96.

13. McCarthy PM, Manjunath A, Kruse J, Andrei AC, Li Z, McGee EC Jr, et al Should paroxysmal atrial fibrillation be treated during cardiac surgery? J Thorac Cardiovasc Surg. 2013;146:810-23.

14. Gillinov AM, Bhavani S, Blackstone EH, Rajeswaran J, Svensson LG, Navia JL, et al. Surgery for permanent atrial fibrillation: impact of patient factors and lesion set. Ann Thorac Surg. 2006;82:502-13.

15. Damiano RJ Jr, Schwartz FH, Bailey MS, Maniar HS, Munfakh NA, Moon MR et al. The Cox maze IV procedure: predictors of late recurrence. J Thorac Cardiovasc Surg. 2011;141:113-21.

16. Gaynor SL, Schuessler RB, Bailey MS, Ishii Y, Boineau JP, Gleva MJ, et al Surgical treatment of atrial fibrillation: predictors of late recurrence. $J$ Thorac Cardiovasc Surg. 2005;129:104-11.

17. Fayad G, Le Tourneau T, Modine T, Azzaoui R, Ennezat PV, Decoene C, et al Endocardial radiofrequency ablation during mitral valve surgery: effect on cardiac rhythm, atrial size, and function. Ann Thorac Surg. 2005;79:1505-11.

18. Gillinov AM, Bakaeen F, McCarthy PM, Blackstone EH, Rajeswaran J, Pettersson G, et al. Surgery for paroxysmal atrial fibrillation in the setting of mitral valve disease: a role for pulmonary vein isolation? Ann Thorac Surg. 2006:81:19-26; discussion 27, 18 .

19. Gillinov AM, McCarthy PM, Blackstone EH, Rajeswaran J, Pettersson G Sabik JF, et al. Surgical ablation of atrial fibrillation with bipolar radiofrequency as the primary modality. J Thorac Cardiovasc Surg. 2005;129:1322-9.

20. Halkos ME, Craver JM, Thourani VH, Kerendi F, Puskas JD, Cooper WA, et al Intraoperative radiofrequency ablation for the treatment of atrial fibrillation during concomitant cardiac surgery. Ann Thorac Surg. 2005;80:210-5; discussion 215-6.

21. Wisser W, Khazen C, Deviatko E, Stix G, Binder T, Seitelberger R, et al Microwave and radiofrequency ablation yield similar success rates for treatment of chronic atrial fibrillation. Eur J Cardiothorac Surg. 2004;25:1011-7.

22. Worku B, Pak SW, Cheema F, Russo M, Housman B, Van Patten D, et al Incidence and predictors of pacemaker placement after surgical ablation for atrial fibrillation. Ann Thorac Surg. 2011;92:2085-9.

23. Pecha S, Schäfer T, Yildirim Y, Ahmadzade T, Willems S, Reichenspurner H, et al. Predictors for permanent pacemaker implantation after concomitant surgical ablation for atrial fibrillation. Thorac Cardiovasc Surg. April 6, 2013 [Epub ahead of print].

24. Hanke T, Charitos EI, Stierle U, Karluss A, Kraatz E, Graf B, et al. Twenty-fourhour Holter monitor follow-up does not provide accurate heart rhythm status after surgical atrial fibrillation ablation therapy: up to 12 months experience with a novel permanently implantable heart rhythm monitor device. Circulation. 2009;120(11 Suppl):S177-84.

25. Hindricks G, Pokushalov E, Urban L, Taborsky M, Kuck KH, Lebedev D, et al; XPECT Trial Investigators. Performance of a new leadless implantable cardiac monitor in detecting and quantifying atrial fibrillation: results of the XPECT trial. Circ Arrhythm Electrophysiol. 2010;3:141-7.

26. Haïssaguerre M, Jaïs P, Shah DC, Takahashi A, Hocini M, Quiniou G, et al. Spontaneous initiation of atrial fibrillation by ectopic beats originating in the pulmonary veins. N Engl J Med. 1998;3:659-66. 